\title{
BORRACHA NATURAL E NANOCOMPÓSITOS COM ARGILA
}

\author{
Márcia Maria Rippel* \\ Instituto de Química, Universidade Estadual de Campinas, CP 6154, 13084-971 Campinas - SP, Brasil \\ Fábio do Carmo Bragança \\ Departamento de Química, Centro de Ciências Exatas e Tecnológicas, Universidade Federal de Viçosa, 36560-000 Viçosa - MG, Brasil
}

Recebido em 15/1/09; aceito em 12/3/09; publicado na web em 2/4/09

\begin{abstract}
NATURAL RUBBER AND NANOCOMPOSITES WITH CLAY. The natural rubber is a strategic material which can not be replaced by synthetic rubber in many technological applications. Brazil is a rubber importer, but new techniques of cultivation, breeding and diversification of producing species can reverse this situation. One of the best ways to add value to this commodity is nanotechnology. The production of nanocomposites is already a reality and shows that the sustainable use of this natural resource can lead to new products and boost the national agribusiness setting labor-qualified in the field.
\end{abstract}

Keywords: natural rubber; nanocomposites; sustainability.

\section{BORRACHA NATURAL}

A borracha natural (NR) é um polímero de poli(cis-1,4-isopreno) e apresenta propriedades únicas devido a sua estrutura intrínseca, alta massa molar e presença de outros componentes minoritários como proteínas, carboidratos, lipídios e minerais presentes no látex. Cerca de 2500 plantas produzem látex, mas o látex da Hevea brasiliensis se constitui na única fonte comercial importante de látex de borracha natural. ${ }^{1}$

A borracha natural é um material estratégico, pois não é substituída por borrachas sintéticas (poli(butadieno-estireno), borracha butílica, policloropreno e poli-isopreno) em muitas aplicações. Isto se deve a dois fatores: a) suas propriedades especiais (resiliência, elasticidade, flexibilidade, resistência à abrasão, ao impacto e à corrosão, fácil adesão a tecidos e aço e impermeabilidade, propriedades isolantes de eletricidade, impermeabilidade a líquidos e gases, capacidade de dispersar calor e maleabilidade a baixas temperaturas); b) relação de preço versus desempenho das borrachas sintéticas que se equiparem à borracha natural. ${ }^{1-3}$

Por isso a borracha natural vem sendo utilizada em mais de $50 \mathrm{mil}$ produtos, em aplicações como adesivos, pneumáticos, luvas descartá- veis, material cirúrgico (tubos intravenosos, seringas, estetoscópios, cateteres e esparadrapos), preservativos, pisos e revestimentos, impermeabilização de fios e tecidos etc. ${ }^{1-3} \mathrm{O}$ látex natural centrifugado é aplicado na confecção dos mais variados produtos, de acordo com a tecnologia disponível. ${ }^{4}$ Um exemplo prático da importância da borracha natural está na fabricação de pneus para caminhões, ônibus e aviões, que não podem ser feitos com borracha sintética devido à drástica diminuição de suas propriedades.

A Tabela 1 apresenta uma lista com algumas das principais fontes de látex natural.

Apesar de a Hevea brasiliensis ser a fonte mais importante de borracha natural, alguns fatores destacam a importância de se desenvolver fontes alternativas para este material: ${ }^{1,4}$

1. a incidência do fungo Microcyclus ulei, causador do mal-dasfolhas nas seringueiras, que acelerou o fim da produção em larga escala da borracha da Hevea brasiliensis na Amazônia. Há uma certeza entre alguns pesquisadores, no Brasil e no exterior, de que esta doença em algum momento poderá alcançar as plantações da Ásia. ${ }^{1,9}$ Um intenso esforço tem sido feito na pesquisa e melhoramento genético de clones da Hevea para que tenham resistência ao fungo e isto será discutido mais detalhadamente ao longo deste artigo.

Tabela 1. Principais fontes de produção de borracha natural ${ }^{1,5,6}$

\begin{tabular}{|c|c|c|c|c|}
\hline Fonte & País de origem & $\begin{array}{l}\text { Conteúdo de sólidos / \% } \\
\text { (massa molar média/kDa) }\end{array}$ & $\begin{array}{l}\text { Produção } \\
\text { (t/ano) }\end{array}$ & $\begin{array}{c}\text { Produção } \\
\left(\mathrm{kg} \mathrm{ha}^{-1} \mathrm{ano}^{-1}\right)\end{array}$ \\
\hline Hevea brasiliensis (seringueira) & Brasil $^{\#}$ & $30-50(1310)$ & $9.789 .000(2007)$ & $500-3000$ \\
\hline Parthenium argentatum (guaiule) & $\begin{array}{l}\text { México e sudoeste dos } \\
\text { Estados Unidos }\end{array}$ & $3-12(1280)$ & $2.600 .000(1988)^{7}$ & $300-2000$ \\
\hline Manihot glaziovii (maniçoba) & Brasil & $3-12(1000-1500)^{8}$ & -- & -- \\
\hline $\begin{array}{l}\text { Ficus elastica, F. ovata, F. pumila, F. volgelii } \\
\text { (figueira-da-borracha ou borracha indiana) }\end{array}$ & Nigéria & $15-28(--)$ & -- & -- \\
\hline $\begin{array}{l}\text { Taraxacum kok-saghyz (dente-de-leão } \\
\text { russo) }\end{array}$ & Rússia & Até 30 (2180) & $3000(1943)$ & $150-500$ \\
\hline Solidago altissima (goldenrod) & Estados Unidos & $5-12$ na raiz $(160-240)$ & -- & $110-155$ \\
\hline
\end{tabular}

\# Entretanto a maior área cultivada está no Sudeste Asiático. 
2. As borrachas sintéticas são derivadas de petróleo e as incertezas a respeito da disponibilidade e preço do petróleo juntamente com uma alta demanda de borracha por parte de economias que rapidamente se expandiram (China e Índia) ${ }^{4}$ têm levado a um rápido aumento nos preços das borrachas natural e sintética. A borracha sintética possui quase a mesma composição química da borracha natural e as suas propriedades físicas são adequadas a alguns manufaturados, porém são inferiores nos casos de luvas cirúrgicas, preservativos, pneus de automóveis, caminhões, aviões e revestimentos diversos. ${ }^{10}$

3. As plantações ou cultivos de seringueira na Malásia estão sendo trocados por plantações de palma para extração do óleo, mais lucrativo, devido à demanda por biocombustível.

4. A coleta do látex de árvores requer mão-de-obra intensa de trabalhadores treinados e não pode (até o presente) ser mecanizada, necessitando ainda de sangria diária de centenas de árvores por trabalhador.

Outro aspecto relativo ao desenvolvimento de fontes alternativas de borracha natural se refere à alergia atribuída às proteínas no látex da Hevea. Cerca de $6 \%$ da população mundial sofre ou poderá sofrer de alergia ao látex. Entre os profissionais de saúde, cerca de $17 \%$ correm o risco de sofrer alguma reação alérgica à borracha da Hevea, usada nas luvas cirúrgicas. ${ }^{1}$

Além da seringueira somente duas outras espécies produzem grandes quantidades de borracha com alta massa molar: um arbusto chamado guaiule (Parthenium argentatum) e o dente-de-leão russo (Taraxacum koksaghyz). Estas plantas foram consideradas fontes promissoras de borracha natural, de tal forma que receberam grandes programas de pesquisa, especialmente no período da II Guerra Mundial. Outras plantas produtoras de borracha ou ainda não foram estudadas suficientemente para determinar sua utilidade ou produzem borracha de qualidade inferior. ${ }^{1}$ Uma terceira planta, a Solidago altissima (goldenrod) também foi explorada comercialmente entre as décadas de 30 e 40 no século XX. Com o final da Guerra, a exploração destas espécies perdeu o interesse comercial devido ao retorno da borracha da Hevea da Ásia. As borrachas de guaiule e de dente-deleão russo não são nativas da biodiversidade brasileira.

No entanto, um comentário a respeito da borracha de guaiule é pertinente: a borracha produzida é de alta qualidade, com uma massa molar semelhante à da Hevea e hipoalergênica (desde que as proteínas sejam removidas). O cultivo, a colheita e produção do látex são completamente mecanizados. Por outro lado, a planta apresenta algumas desvantagens: é parcialmente domesticada e não tolera baixas temperaturas de invernos rigorosos. O processamento do arbusto de guaiule é tecnicamente complicado e envolve custos operacionais e investimentos significativos, e o látex necessita da eliminação de resinas, as quais só podem ser removidas por extração com um solvente. O preço da borracha ou látex de guaiule não é de conhecimento público, mas estima-se que os custos de cultivo, coleta e transporte cheguem a US $\$ 2,85$ por $\mathrm{kg}$ de borracha ou látex, superior aos US\$1,98 da Hevea $(\mathrm{R} \$ 4,57$ o kg do granulado escuro brasileiro GEB-1 em dezembro de 2008). ${ }^{11,12}$

Mesmo com essas desvantagens, a empresa americana Yulex, juntamente com o governo daquele país e um instituto de pesquisa em genética, assinou recentemente um acordo para desenvolver e testar em campo plantas de guaiule com maior produtividade de látex natural e maior biomassa. A empresa afirma que as plantas geneticamente selecionadas poderão ter uma maior produtividade do que a seringueira na Ásia. Outra vantagem seria usar a planta também na produção de etanol (álcool). ${ }^{13,14}$

A exploração da borracha de maniçoba no Brasil já teve um pico durante a II Guerra Mundial. A participação das maniçobas na economia regional do semi-árido nordestino iniciou-se com a descoberta do látex destas plantas e sua utilização na indústria da borracha, sendo o auge da cultura entre os anos de 1845 e 1916. Embora a produção tenha se baseado no extrativismo, algumas plantações foram estabelecidas no início do século XX, especialmente na Bahia. O primeiro ciclo de extração continuou até 1918, interrompeu-se entre o final da I Guerra e o início da II Guerra Mundiais, ressurgindo durante a II Guerra, quando o Brasil produziu pneus com borracha de maniçoba. ${ }^{15}$

Três espécies de maniçobas, a maniçoba-do-Piauí (Manihot caerulescens Pohl), a maniçoba-de-Jequié (Manihot dichotoma Ule) e a maniçoba-do-Ceará (Manihot glaziovii Muell. Arg.), foram exploradas para extração do látex. Trata-se de arbustos ou pequenas árvores restritos à região do semi-árido nordestino, agreste e norte de Minas Gerais, na divisa com a Bahia. As plantas distribuem-se preferencialmente pela caatinga, carrascos nordestinos e vegetação xerófila do nordeste de Minas. ${ }^{15}$

No período de 1956 a 1971, a produção de látex da maniçoba-doPiauí correspondeu a $42 \%$ do total desta cultura produzido no país. Oficialmente a exploração do látex no Piauí se encerrou em 1972. ${ }^{15}$

Atualmente a maniçoba-do-Ceará é utilizada apenas como planta forrageira para gado. ${ }^{15}$ Porém as árvores desta maniçoba podem ser sangradas com idades entre 4 e 5 anos para coleta do látex ${ }^{16}$ e a massa molar média é da mesma ordem da borracha da Hevea.

Uma planta de borracha ideal deveria produzir durante o ano todo, ter crescimento rápido, ser capaz de produzir grande quantidade de biomassa e com uma alta concentração de borracha. Atualmente, a melhor e principal espécie produtora de borracha natural é a Hevea brasiliensis. No entanto, o Brasil hoje cultiva clones trazidos da Malásia, e importa do sudeste asiático mais da metade do que consome.

\section{Hevea brasiliensis (seringueira)}

O gênero Hevea é um membro da família Euphorbiaceae que compreende outros gêneros importantes de culturas tropicais, tais como Ricinus (mamona) e Manihot (mandioca). A classificação atual do gênero Hevea inclui 11 espécies, dentre as quais se destaca a Hevea brasiliensis que apresenta maior capacidade produtiva e variabilidade genética para resistência a doenças. ${ }^{10}$

Por isso mesmo o látex da Hevea brasiliensis fornece aproximadamente $99 \%$ da produção mundial de borracha natural. O látex acha-se em minúsculos vasos no córtex interno da casca da árvore o qual fica abaixo do córtex externo, ${ }^{17}$ sendo que a borracha se encontra situada nas partículas de borracha citoplasmáticas. ${ }^{18} \mathrm{O}$ látex da Hevea é um sistema polidisperso, no qual partículas negativamente carregadas de vários tipos estão suspensas em um soro.

A participação da borracha natural no mercado de borracha subiu de $30 \%$ nos anos 80 para os atuais $40 \% .{ }^{1}$ No Brasil entre 1992 e 2002 foram importados 1,2 milhões de toneladas de borracha natural, sendo que a produção interna foi de 693,5 mil toneladas. ${ }^{19}$ Isto significa que o Brasil gastou naquela década mais de US\$ 1 bilhão com a importação de borracha natural. Já em 2006 foram gastos US\$ 385 milhões, o que indica um aumento na produção interna, enquanto que em 2007 o valor das importações voltou a subir chegando a US\$ 489 milhões em novembro. ${ }^{20}$ Em 2002 o consumo foi de 250 mil toneladas e a produção interna, 95 mil toneladas; em 2004 o consumo foi de 287 mil toneladas e há uma previsão de que em 2010 o consumo atinja 500 mil toneladas. ${ }^{21}$ Se não houver um aumento no número de novos seringais plantados no Brasil, esta dependência de importação pode ser tornar mais crítica e maior, pois $72 \%$ da borracha consumida no mundo é destinada à produção de pneus. ${ }^{21}$ Atualmente, $90 \%$ da produção mundial de borracha se encontra nos países do Sudeste Asiático. O Brasil é hoje o $9^{\circ}$ produtor mundial de borracha natural, atrás de Tailândia, Indonésia, Malásia, Índia, China e Vietnã., ${ }^{4,2}$

A produção nacional está concentrada nos estados de São Paulo (34\%), Bahia (15\%), Mato Grosso (29\%), Espírito Santo (4,7\%), Minas Gerais $(2,9 \%)$ e Goiás $(2,4 \%) .{ }^{4}$ No Brasil o consumo de borracha 
natural vem crescendo $6 \%$ ao ano, acima da média mundial que é de 4\%. Com o aumento no consumo, a importação também cresce a uma taxa média anual de $8 \%$. Na mesma velocidade vinha subindo o preço da borracha natural comparada com a sintética, e os preços só recuaram em função da crise econômica no segundo semestre de 2008 . O estoque mundial de borracha natural é cerca de 2000 toneladas. $^{6}$

\section{Processo de extração e concentração do látex natural}

$\mathrm{O}$ látex é coletado por um processo chamado sangria (tapping). Neste processo, uma faca especialmente desenhada é usada para remover fatias da casca da superfície de um corte feito na árvore a uma profundidade de cerca de $1 \mathrm{~mm}$ do câmbio. Tanto a produção quanto as características do látex são afetadas pela frequência de corte, da altura do painel e da periodicidade de sangria.

O látex pode coagular espontaneamente ou com auxílio de coagulantes como, por exemplo, soluções eletrolíticas, produzindo a borracha coagulada. Se o látex não for imediatamente processado, deve ser adicionada a ele uma pequena quantidade de um preservativo (por exemplo, uma solução básica) para evitar a coagulação espontânea do látex.

O látex extraído apresenta uma concentração de borracha de 30$40 \%$ em massa, sendo o restante constituído principalmente de água e há alguns fatores importantes que justificam a concentração do látex de campo. Na prática a concentração do látex chega a $60 \%$ em massa ou maior, tornando o produto viável economicamente para ser transportado e com qualidades apropriadas para uso em muitos processos industriais. Os métodos mais utilizados para concentrar o látex são: evaporação, creaming, eletrodecantação e centrifugação. Este último é o mais utilizado industrialmente. O látex concentrado é utilizado na fabricação de produtos por imersão, moldagem ou casting.

\section{Melhoramento genético}

O Brasil perdeu o posto de maior produtor de borracha natural por conta do contrabando de sementes de seringueira para a Ásia. Lá foram realizados os primeiros plantios cultivados da Hevea. Um outro fator foi responsável pela perda da hegemonia e está relacionado com o fungo Microcyclus ulei, causador do mal-das-folhas da seringueira, doença que além de diminuir a produção de látex pode levar a planta à morte. Entretanto, pesquisas realizadas ao longo de anos com clones de Hevea mostraram que alguns deles são resistentes ao mal. Há 14 anos, a PMB - Plantações Michelin da Bahia - unidade agroindustrial da maior fabricante mundial de pneus, desenvolve um estudo com seringueiras resistentes à doença, na Bahia. ${ }^{9}$ Já foram obtidas 14 variedades resistentes à doença, das quais quatro já estão sendo trabalhadas em escala semi-industrial. A empresa investe cerca de um milhão de reais por ano nos estudos e conta com a parceria do Cirad Centro de Cooperação Internacional em Pesquisas Agronômicas para o Desenvolvimento - localizado em Montpellier, na França. Além do instituto francês, a Michelin tem parceria com universidades e órgãos de pesquisa brasileiros. O trabalho já está sendo observado de perto pelos países do Sudeste Asiático. Se o fungo aparecer nas plantações dos maiores produtores mundiais de borracha natural, calcula-se que o impacto da propagação do mal-das-folhas na região irá afetar a vida de pelo menos 30 milhões de pessoas que vivem da cultura. Atualmente cerca de $75 \%$ da produção mundial está localizada em áreas sujeitas ao mal-das-folhas. ${ }^{4}$

Além da busca de clones resistentes, uma outra forma de controle está na aplicação de defensivos químicos, porém há problemas quanto ao custo desta aplicação. Para que o defensivo chegue às folhas é preciso utilizar helicópteros ou aviões agrícolas. Em uma plantação comercial esse método é muito caro tornando-o inviável, dentro do quadro atual.

No âmbito do projeto do Centro de Pesquisas do Cacau (CEPEC) da Comissão Executiva do Plano da Lavoura Cacaueira (CEPLAC) da Bahia destaca-se o clone SIAL 1005 com elevada produção de borracha seca e tolerância ao Microcyclus ulei. ${ }^{23}$ Em outros estados, como Goiás e Mato Grosso, a situação não é diferente. Em Goiás destacam-se os clones RRIM 600, IAN 2880 e IAN 2878 com produtividade acima de $6,9 \mathrm{~kg} / \mathrm{planta} / \mathrm{ano}$ ou $3000 \mathrm{~kg} / \mathrm{ha} / \mathrm{ano}$. Em Mato Grosso a recomendação de plantio de clones depende da região do estado, em função de suas condições climáticas. ${ }^{4}$ No Espírito Santo o clone recomendado para produção em larga escala é o FX3864, pois apresenta a maior produtividade dentre todos os clones no estado e que está acima de 1600 kg/ha/ano. Em São Paulo os clones recomendados para plantio em larga escala são o RRIM 600 e PR255.

Além do Cirad, outras instituições têm participado do desenvolvimento de clones resistentes e mais produtivos, como a Embrapa - Empresa Brasileira de Pesquisa em Agropecuária; o Cenargen - Centro Nacional de Recursos Genéticos; o IAC - Instituto Agronômico de Campinas e, a ESALQ - Escola Superior de Agricultura Luiz de Queiroz.

Mas um clone, além de ser resistente ao fungo, deve apresentar alta produtividade. Neste sentido o diagnóstico do látex é muito importante para determinar a produtividade dos clones. As seguintes variáveis são analisadas: teor de sacarose, teor de tióis, extrato seco, $\mathrm{pH}$, teor de fósforo inorgânico, teor de magnésio, potencial redox e sólidos totais. Este tipo de análise também pode auxiliar na escolha precoce para produção, por mostrar uma correlação positiva entre os diagnósticos nas fases adultas e jovens. ${ }^{4}$

De acordo com Ferreira, "as análises de extrato seco, conteúdo de sacarose, conteúdo de fósforo inorgânico e conteúdo de tióis do látex indicam o estado fisiológico da Hevea, podendo através desse conhecimento aperfeiçoar a produção de borracha. $\mathrm{O}$ estudo da cinética de regeneração com o intervalo de tempo entre duas sangrias consecutivas, utilizando as variáveis citadas, mostra a relação entre a atividade biológica dos sistemas laticíferos e a reconstituição dos seus componentes. Esse tipo de análise permite ao produtor dominar a produção do látex, evitando perdas por super-exploração, garantindo a boa saúde das árvores e, consequentemente, produção ótima e prolongada. O DRC (dry rubber content) representa a quantidade de borracha seca presente no látex e reflete a regeneração do látex no interior dos laticíferos. Um baixo conteúdo de borracha seca pode indicar uma discreta regeneração in situ do isopreno. Em casos de exploração intensiva, os valores baixos dessa variável indicam uma regeneração insuficiente. O conteúdo de fósforo inorgânico $(\mathrm{Pi})$ está relacionado com a atividade metabólica dos sistemas laticíferos do látex, em particular a energia de síntese do isopreno. Os valores de Pi tendem a cair quando os sistemas laticíferos se tornam menos ativos. Os tióis (R-SH) são moléculas orgânicas que contêm enxofre e apresentam papel importante na proteção das células contra a oxidação por radicais livres. As moléculas de tióis neutralizam formas "tóxicas" de oxigênio resultantes do metabolismo celular, as quais podem prejudicar genes, destruindo organelas e degradando membranas, prejudicando desta forma o funcionamento das células. $\mathrm{O}$ açúcar, principalmente na forma de sacarose, é a molécula básica para a síntese do isopreno e também para a obtenção de energia na forma de ATP para as células. Em geral, a baixa concentração de sacarose indica que a molécula de açúcar está sendo rapidamente consumida e a árvore não tem tempo suficiente para repor a quantidade de açúcar perdida." ${ }^{24}$

Alguns aspectos sócio-ambientais devem ser considerados no cultivo e exploração sustentável das seringueiras tendo em vista a produção de materiais avançados

$\mathrm{O}$ desenvolvimento de novos materiais avançados baseados na borracha natural deverá produzir um forte impacto socio-econômico e ambiental na cultura da seringueira: 
- a geração de emprego e rendas $\Rightarrow$ com o aumento na heveicultura, mais pessoas serão empregadas, pois para cada 4 hectares plantados é necessário uma pessoa para extrair o látex. Embora a seringueira leve de 7 a 8 anos para produzir o látex, ela pode ser cultivada consorciada com outras culturas como café, soja, palmito, maracujá, entre outras, garantindo a renda e sustentabilidade do produtor até que a planta atinja o período produtivo. A seringueira pode ser explorada por 30 anos e em qualquer época do ano. ${ }^{13,25}$

- redução nas importações $\Rightarrow$ devido à importação, a borracha natural é o segundo item de maior saldo negativo na balança comercial do agronegócio brasileiro, chegando a US\$ 466 milhões no acumulado de janeiro a setembro de 2008 na importação de 174 mil toneladas. ${ }^{13,26}$

O cultivo da seringueira ajuda a evitar processos de erosão, protege mananciais e contribui para o desenvolvimento da fauna e da flora servindo como habitat. A seringueira também vem recebendo destaque quanto ao fato de ajudar a diminuir a presença de gases poluentes na atmosfera, especialmente o $\mathrm{CO}_{2}$, através do sequestro de carbono, sendo que desde o $6^{\circ}$ ou $7^{\circ}$ meses após o plantio das mudas já começa a absorvê-lo da atmosfera. Nesse sentido, pesquisas realizadas na Malásia demonstraram que o carbono sequestrado por cultivos de seringueiras é equivalente ao carbono capturado por florestas naturais. ${ }^{20} \mathrm{O}$ consumo de energia para produzir 1 tonelada de borracha natural é menos de um sexto do que se gasta para produzir 1 tonelada de borracha sintética, de acordo com a Tabela 2 , considerando parâmetros como coleta, processamento e transporte.

Tabela 2. Comparação entre o consumo de energia necessária para produzir vários tipos de borracha ${ }^{27}$

\begin{tabular}{lc}
\hline Material & Energia necessária em GJ/t \\
Borracha natural & 16 \\
Polibutadieno & 108 \\
Polipropileno & 110 \\
Policloropreno & 120 \\
PSBR & 130 \\
EPDM & 142 \\
Poliuretano & 174 \\
Borracha butílica & 174 \\
\hline
\end{tabular}

\section{Levantamento estatístico em bases de dados}

A borracha natural é objeto de intenso estudo na literatura, principalmente quanto aos seus processos de vulcanização, cristalização e estudos na área biológica, na identificação e eliminação das proteínas causadoras de alergias. A Tabela 3 apresenta o número de referências recuperadas em duas bases de dados acadêmicas e em outras duas, de patentes.

Do total de referências recuperadas no SciFinder Schoolar e na base European Patent Office com as palavras-chave natural rubber, a maioria são relativas a patentes de grandes empresas pneumáticas como Bridgestone, Yokohama, Sumitomo, Goodyear e Toyo. Na base Web of Science as cinco instituições que mais publicaram artigos sobre borracha natural foram Universiti Sains Malaysia (Malásia), Mahidol University (Tailândia), Prince of Songkla (Tailândia), Mahatama Gandhi University (Índia) e Chulalongkorn University (Tailândia).

As cinco instituições que mais publicaram artigos sobre nanocompósitos de borracha natural foram Indian Institute of Technology (Índia), Beijing University of Chemical Technology (China), CSIC - Consejo Superior de Investigaciones Científicas (Espanha), University of Grenoble (França), e Rubber Research Institute of India (Índia).

Especificamente em relação à preparação e caracterização de nanocompósitos poliméricos de borracha natural foram recuperados 214 artigos e 13 patentes, o que demonstra o interesse por esta nova tecnologia.

\section{Projetos de pesquisa em borracha ${ }^{28}$}

Instituições no Brasil e no exterior mantêm projetos de pesquisa em borracha natural. Embora não se registre um grande número de artigos e patentes em borracha natural pelo Brasil, chama a atenção o número de projetos de pesquisa em andamento: 5 no Brasil e 7 no exterior. Portanto, há interesse no desenvolvimento e cultivo da Hevea, mas não há um projeto direcionado ao desenvolvimento de materiais.

Estes projetos estão listados a seguir:

a) no Brasil

\section{Projeto Borracha Natural Brasileira}

Informações sobre o setor agroindustrial da borracha natural, com dados atualizados do mercado da borracha e derivados no Brasil e no mundo - www.borrachanatural.agr.br

Programa Seringueira - IAC

Instituto Agronômico de Campinas, SP. Voltado à pesquisa, ao estudo e melhoramento genético da borracha natural e seringueira - www.iac.sp.gov.br

\section{Projeto Tecbor}

Tecnologia alternativa para produção de borracha na Amazônia, sob coordenação e desenvolvimento do Lateq do Instituto de Química da Universidade de Brasília - www.unb.br/iq/labpesq/lateq Câmara Setorial da Cadeia Produtiva da Borracha Natural ${ }^{29}$

A Câmara vinculada ao Ministério da Agricultura foi instalada em 2005 e prioriza a solução dos seguintes problemas: sanidade e proteção de plantas; melhoramento genético (produção e produtividade de borracha, produção de madeira, sequestro de carbono); agronomia e manejo de plantas; zoneamento ecológico e econômico (regionalização do cultivo); transformação da produção, qualidade e

Tabela 3. Levantamento estatístico em bases de dados até janeiro/2009

\begin{tabular}{|c|c|c|c|c|c|}
\hline \multirow[t]{2}{*}{ Palavras-chave } & \multirow{2}{*}{$\begin{array}{l}\text { SciFinder } \\
\text { Scholar }\end{array}$} & \multicolumn{2}{|c|}{ Web of Science } & \multirow[t]{2}{*}{ INPI } & \multirow{2}{*}{$\begin{array}{c}\text { European Patent } \\
\text { Office }\end{array}$} \\
\hline & & Brasil & Mundo & & \\
\hline Natural rubber & 42409 & 168 & 6204 & 202 & 20285 \\
\hline Natural rubber and Hevea* & 637 & 37 & 345 & 1 & 51 \\
\hline Natural rubber and composite* & 9289 & 18 & 700 & 2 & 725 \\
\hline Natural rubber and nanocomposite* & 424 & 5 & 214 & 3 & 13 \\
\hline Natural rubber and material* & 10172 & 34 & 889 & 48 & 6999 \\
\hline
\end{tabular}


certificação da borracha; financiamento do cultivo e comercialização da borracha - www.agricultura.gov.br/

\section{Programa Seringueira - COHEVEA/Embrapa ${ }^{30}$}

Programa de melhoramento genético da seringueira visando a obtenção de plantas com alta produção e resistente a doenças. Foi assim que, através de cruzamentos controlados e seleção de plantas, foram obtidos clones indicados para plantios nas mais variadas condições climáticas - www.cnps.embrapa.br/cohevea/home.htm

\section{b) no exterior}

DIK - Deutsches Institut für Kautschuktechnologie e.V.

Instituto alemão de pesquisa e desenvolvimento na área da tecnologia da borracha - www.dikautschuk.de

\section{IRRDB - International Rubber Research and Development Board}

Rede virtual de pesquisa e desenvolvimento em borracha natural, cobrindo $95 \%$ da produção de borracha natural no mundo - www. irrdb.com.

\section{MRB - Malaysian Rubber Board}

Pesquisa e desenvolvimento, consultoria, serviços, transferência de tecnologia, treinamento, cursos, seminários e publicações - www. lgm.gov.my

\section{MRPMA - Malaysian Rubber Products Manufacturing}

\section{Industry}

Organização representativa da indústria de artefatos de borracha na Malásia. O diretório é amplamente reconhecido e usado para a busca de informação e referência - www.mrpma.com

\section{Rubber Board of India}

Trata-se de um conselho constituído pelo Governo da Índia para o desenvolvimento da indústria da borracha natural do país http://rubberboard.org.in/index.asp

\section{Rubber Division}

Publica periódicos e livros. Realiza cursos e seminários - www. rubber.org

\section{Universidade de Akron - EUA}

Informações sobre professores e conteúdos desenvolvidos no Departamento de Polímeros. Acesso à base de dados da biblioteca www2.uakron.edu/cpspe

\section{Principais pesquisadores e instituições envolvidas com a pesquisa de nanomateriais de borracha natural}

\section{a) Nacionais}

Um levantamento na Plataforma Lattes do CNPq recuperou 6 grupos de pesquisa envolvidos com o desenvolvimento de materiais nanotecnológicos nas seguintes universidades e centros de pesquisa: Unicamp (grupo de Fernando Galembeck e Márcia M. Rippel), UFRJ (Regina Célia Reis Nunes), Embrapa (Luis H. C. Mattoso), UFABC (Mariselma Ferreira), Faenquil (Amilton Martins dos Santos) e USP (Nicole Demarquette). A atuação destes grupos segue linhas diferenciadas: modificação de látex natural e incorporação de nanocargas, estudo em nanoescala das propriedades da borracha natural, nanocompósitos de borracha natural com nanofibras de celulose, obtenção de látices de borracha natural com nanopartículas minerais.

O grupo de Regina C. R. Nunes do IMA/UFRJ pesquisa a formação de nanocompósitos especiais e nanocompósitos de borrachas, tanto natural quanto sintéticas, com nanofibras de celulose. Os processos para obtenção geraram duas patentes ${ }^{31,32} \mathrm{e}$ os produtos podem ser obtidos na forma de pós, grupos e fibras. Dependendo do processo usado, nanofibras dispersas na matriz elastomérica são obtidas. ${ }^{33,34}$

O grupo de Luis H. C. Mattoso da Embrapa/Instrumentação Agropecuária se dedica à pesquisa de materiais compósitos e nanocompósitos de borracha natural e com outros polímeros condutores como, por exemplo, o desenvolvimento de filmes condutores de eletricidade de borracha natural com negro de fumo com potencial aplicação como transdutores em sensores de pressão. ${ }^{35}$

O grupo de Fernando Galembeck desenvolveu um método inovador de preparação de nanocompósitos a partir de látices e dispersões aquosas com nanopartículas de argilas por mistura mecanoquímica. $\mathrm{O}$ desenvolvimento de tecnologias para preparação de nanocompósitos de borracha natural com argilas já é corrente neste laboratório. ${ }^{36-38}$

O que diferencia estes processos das demais técnicas de preparo de nanocompósitos é que não é necessária a etapa de modificação química do mineral inorgânico lamelar, rota tradicionalmente utilizada. Dada a flexibilidade da tecnologia, é possível preparar dispersões de argila esfoliada com látices por meio de um processo simples, limpo e econômico.

A patente PI 0301193-3 de autoria deste grupo foi licenciada em 2005 para a empresa Orbys Desenvolvimento de Tecnologia de Materiais Ltda (São Paulo) que, através de convênio com o grupo da Unicamp, desenvolve e pesquisa produtos à base de nanocompósitos de borracha natural para os mais diversos setores da indústria.

Quanto à pesquisa de materiais com borracha de maniçoba, apenas 63 referências foram recuperadas com as palavras-chave manihot glaziovii and rubber no SciFinder Schoolar, 13 na Web of Science e nenhuma nas bases de patentes European Patent Office e INPI, o que demonstra que conjuntamente com o declínio econômico houve um desinteresse pela utilização do látex e borracha de maniçoba em pesquisa e produção de artefatos.

Das 13 referências recuperadas na Web of Science, 5 são do Brasil e são de pesquisas realizadas pelos grupos de pesquisa de Judith Feitosa (UFC), Nágila Ricardo (UFC), Marcos Alcântara (UnB), Glaucione Barros (UnB) e André Cardoso (URC).

Sobre cultivo, produtividade e técnicas de exploração da maniçoba não há informação disponível, o que dificulta em parte o julgamento sobre a viabilidade de se produzir látex a partir desta espécie.

\section{b) Internacionais}

O grupo de Sabu Thomas desenvolve compósitos com fibras de sisal e óleo de palma para uso em áreas que necessitam de materiais que dissipem energia eletrostática, em blindagem eletromagnética e outras aplicações eletrônicas. ${ }^{39}$

O grupo de Alain Dufresne ${ }^{40-42}$ pesquisa a obtenção de compósitos de borracha natural com nanocristais de amido de forma a produzir materiais com maior módulo e tensão na ruptura, mas que ainda mantenha uma elasticidade superior a compósitos convencionais com negro de fumo, sílica e pós de cálcio.

O grupo de Muhd Zuazhan Yahya ${ }^{43}$ desenvolve filmes de polimetilmetacrilato com $50 \%$ de borracha natural epoxidada (ENR) dopados com sais de lítio $\left(\mathrm{LiCF}_{3} \mathrm{SO}_{3}\right)$. A incorporação de $50 \%$ de ENR aumentou a condutividade elétrica dos filmes em até duas ordens de magnitude à temperatura ambiente. Além disso, a borracha oferece maior elasticidade, diminui o brilho e confere adesão ao filme, tornando-o adequado para promover um excelente contato entre eletrodo e eletrólito em baterias.

Outros exemplos de nanocompósitos de borracha natural em estudo envolvem a adição de nanotubos de carbono de parede simples e múltipla e nanopartículas de carbeto de silício ( $\mathrm{SiC}$ ) como agentes de reforço. ${ }^{44-48}$

\section{NANOCOMPÓSITOS DE BORRACHA NATURAL E ARGILA}

A incorporação de nanopartículas à borracha natural pode proporcionar melhoria em propriedades como: módulo elástico, ${ }^{49-54}$ resistência a solvente e ultravioleta, ${ }^{55-58}$ propriedade de barreira a 
gases e líquidos, ${ }^{59-62}$ estabilidade dimensional, ${ }^{63,64}$ e de resistência à chama. ${ }^{65-67}$ Além disso, o aumento nas propriedades físicas pode ser conseguido com a incorporação de uma quantidade bem menor de material (2-5\% em massa) em relação à quantidade geralmente empregada para reforçar a borracha (10-30\% em massa), pois as nanopartículas apresentam elevada área superficial por unidade de volume e, em consequência disto, um elevado número de pontos disponíveis para interações entre elas e a matriz polimérica ${ }^{68}$ Estas interações interfaciais variam dependendo do tipo de polímero, do tipo de nanopartícula e do método de síntese utilizado. Contudo, a borracha natural, principalmente na forma de látex, apresenta características intrínsecas que favorecem a obtenção de nanocompósitos com elevado grau de reforço frente à borracha sólida.

Atualmente existem diferentes técnicas para preparar nanocompósitos (NCP) de borracha natural e nanopartículas, principalmente as argilas. ${ }^{69-73}$ Contudo, o grau de reforço dos nanocompósitos frente à borracha sólida pode variar em função da rota utilizada para sua preparação e de fatores como: a ausência ou pouca interação interfacial entre as fases, devido ao baixo grau de dispersão das lâminas de argila; a utilização de processos de mistura ineficientes; o alinhamento e/ou falta de alinhamento das nanopartículas na matriz; a natureza fractal dos agregados formados; o tipo de substituinte organofílico utilizado para facilitar a separação das lâminas; entre outros.

Varghese e Karger-Kocsis ${ }^{74}$ prepararam nanocompósitos de látex de borracha natural (NR) com $10 \%$ de uma bentonita e uma flúor-hectorita sintética. Os autores atribuíram o aumento no módulo elástico nos nanocompósitos à formação, pela carga nanométrica, de uma estrutura ou esqueleto tridimensional na matriz polimérica.

Wang e colaboradores ${ }^{75}$ prepararam nanocompósitos incorporando argila a látices de NR e policloropreno, seguido da coagulação das dispersões. Os resultados mostraram que os nanocompósitos apresentaram valores de módulo elástico, dureza, tensão na ruptura e propriedade de barreira a gases superiores aos de compósitos preparados com estes polímeros e negro de fumo.

Zhang e colaboradores ${ }^{76}$ patentearam uma metodologia para a preparação de nanocompósitos, onde uma dispersão de argila com teor de sólidos entre 0,2 e 20\% em massa é misturada a uma emulsão polimérica. A dispersão obtida passa por ultrassom durante $10 \mathrm{~min}$, sendo depois coagulada com uma solução eletrolítica. Durante a etapa de mistura, podem ser adicionados ao sistema agentes de acoplamento como trietanolamina, silanos etc., em uma proporção entre 0,5 e $2 \%$ em massa. Com base nesta patente, estes autores publicaram uma série de trabalhos utilizando os mais diversos polímeros elastoméricos, entre eles: borracha nitrílica, ${ }^{77}$ poli(isobutileno-isopreno), ${ }^{78}$ poli(butadieno-estireno), ${ }^{79}$ borracha natural ${ }^{80}$ e poli(etileno-copropileno-co-dieno). ${ }^{81}$

Entre os pesquisadores que utilizaram a mistura mecânica para incorporar a argila à borracha natural aquecida, vulcanizar o nanocompósito durante ou após a incorporação da argila foi um procedimento frequentemente utilizado. ${ }^{82-84}$ Muitos destes trabalhos objetivaram apenas substituir o negro de fumo (utilizado em pneus e mangueiras para líquidos aquecidos) por argila, sem procurar soluções para os problemas ambientais envolvidos com a borracha vulcanizada. De maneira geral, estes trabalhos mostraram que esta substituição aumentou o módulo elástico e alterou a reologia da borracha vulcanizada, além de acelerar o processo de vulcanização em relação ao realizado na presença de negro de fumo. Este tipo de resultado incentivou empresas como a Goodyear a desenvolver processos e produtos nanocompósitos de borracha natural para serem utilizados em pneus, correias, mangueiras e outros artefatos. Um exemplo é a patente US7473728 da Goodyear que se refere à preparação de duas pré-formas elastoméricas prensadas e aquecidas. A primeira composta por borracha butílica e poli(etilenoco-propileno-co-dieno) reforçada com sílica, e a segunda composta por borracha natural e lâminas de argila esfoliadas e alinhadas na matriz. Estas pré-formas são unidas e vulcanizadas para produzir artefatos nanocompósitos. O objetivo é substituir uma quantidade significativa do negro de fumo na borracha, de forma a se conseguir a redução do acúmulo de calor no produto, aumentando assim a durabilidade do pneu e a economia de combustível. ${ }^{85}$

Outras empresas que produzem artefatos de borracha também possuem patentes envolvendo nanocompósitos. A patente JP2003292678 da Bridgestone descreve a preparação de uma dispersão de borracha, argila e um agente de acoplamento do tipo aminossilano solúvel em água. O procedimento é misturar a suspensão aquosa de argila com o látex de borracha natural ou outros látices poliméricos e, em seguida, adicionar à mistura um agente de acoplamento como o ( $\mathrm{N}$-[beta] (aminoetil)[gama]-aminopropilmetildimetóxissilano), seguido da secagem da mistura. ${ }^{86}$

A empresa norte americana InMat ${ }^{\circledR}$ comercializa dispersões de látices naturais e sintéticos com argilas para serem utilizadas como revestimento anticorrosivo e, também, na fabricação de produtos como bolas de tênis (Wilson Double Core ${ }^{\mathrm{TM}}$ ), luvas e máscaras feitas de borracha. ${ }^{87}$

No Brasil a Orbys investe no desenvolvimento de matérias-primas e tranferência de tecnologia para a produção de bolas de tênis (NanoBall $^{\circledR}$ ) e outros produtos nanocompósitos. Desde o licenciamento da patente PI 0301193-3 da Unicamp esta empresa investe em pesquisa e desenvolve produtos nanocompósitos de borracha natural com argila para os mais diversos setores da indústria. A parceria, por meio de convênio de pesquisa com o grupo de Fernando Galembeck na Unicamp gerou entre 2006 e 2008 duas novas patentes, ${ }^{37,38}$ permitindo à Orbys ter um portfólio de produtos. ${ }^{88}$

Além dos processos desenvolvidos em parceria com a Orbys, o grupo de pesquisa de Fernando Galembeck desenvolveu outras metodologias para obtenção de novos produtos nanocompósitos com borracha natural. Durante o doutorado de Fábio C. Bragança ${ }^{89}$ sob sua orientação, foram investigadas as propriedades estruturais de laminados autoadesivos obtidos com a união de filmes de borracha natural e argila com propriedades mecânicas distintas, em função da quantidade de carga incorporada à matriz, mas altamente compatíveis, pois são formados pela mesma matriz polimérica. A Figura 1 mostra uma microtomografia de raios $\mathrm{X}$ do interior de um laminado constituído por 2 filmes de borracha natural com 5\% de argila em massa, entre um filme com $30 \%$ de argila em massa. Como o silício, o alumínio e o sódio presentes na argila possuem densidades eletrônicas superiores a do carbono e outros elementos presentes em quantidade minoritária na borracha natural, quanto maior a quantidade de argila no filme, menor a intensidade do pixel na imagem. Nos filmes com $5 \%$ de argila não é possível observar domínios escuros dispersos na matriz, indicando que os agregados de argila nestes filmes possuem dimensões menores que o poder de resolução do aparelho. Já no filme com $30 \%$ de argila, a elevada quantidade de carga incorporada à matriz faz com que os domínios de argila e de polímero estejam muito próximos tornando a matriz densa e homogênea.

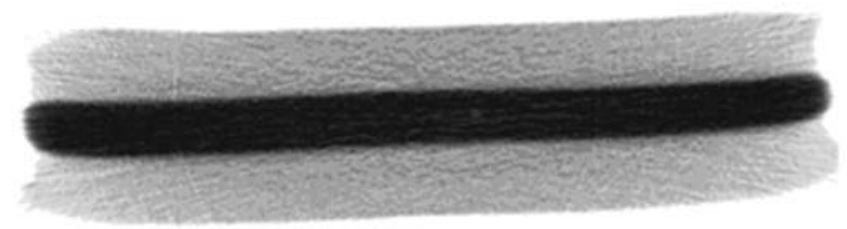

$\overline{1 \mathrm{~mm}}$

Figura 1. Microtomografia de raios $X$ do interior do laminado (dois filmes com $5 \%$ de argila entre um filme com 30\% de argila). Barra de escala: $1 \mathrm{~mm}$ 
As "estrias" observadas na imagem indicam que o processo de formação dos filmes de látex orienta as lâminas de argila segundo o plano de secagem. Outra observação importante é perceber que as interfaces entre os filmes com 5 e 30\% de argila são lisas e homogêneas e não apresentam descolamentos ou defeitos.

Ensaios de tensão-deformação mostraram que um filme de borracha não vulcanizada preparado por casting com 2,0 $\pm 0,2 \mathrm{~mm}$ de espessura apresenta módulo elástico de $0,7 \pm 0,1 \mathrm{MPa}$, enquanto um filme nanocompósito de borracha com $5 \%$ de argila com a mesma espessura apresenta módulo elástico de 3,1 \pm 0,3 MPa. Já os laminados formados por um filme com $30 \%$ de argila entre dois filmes com $5 \%$ de argila (espessura do laminado de 2,0 $\pm 0,2 \mathrm{~mm}$ ) apresentaram módulo elástico de $45 \pm 9 \mathrm{MPa}$.

Para avaliar a compatibilidade entre os filmes, os corpos de prova utilizados nos testes de tensão-deformação foram observados em um microscópio eletrônico de varredura. A Figura 2a mostra que os filmes com $5 \%$ de argila do laminado romperam em seu interior, permanecendo as interfaces fortemente conectadas ao filme com $30 \%$ de argila. Na imagem em maior ampliação (Figuras $2 \mathrm{~b}$ ) pode-se perceber que as interfaces dos filmes externos permaneceram aderidas ao filme interno após o ensaio.
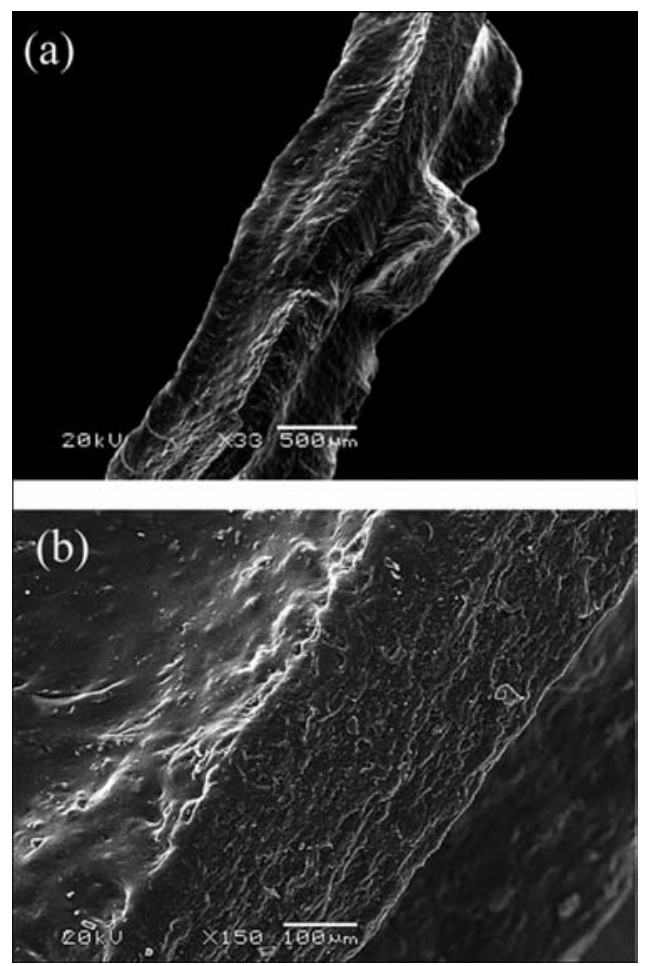

Figura 2. Imagens da região de fratura de um corpo de prova do laminado ensaiado mecanicamente. Barra de escala: $500 \mu \mathrm{m}$. (a) Imagem de elétrons secundários com ampliação de 33 vezes (SEI), (b) imagem de elétrons secundários com ampliação de 150 vezes. Barra de escala: $100 \mu \mathrm{m}$

\section{PERSPECTIVAS SOBRE BORRACHA NATURAL E NANOCOMPÓSITOS}

A nanotecnologia se mostra como uma possibilidade extremamente interessante e versátil de obtenção de centenas de novos materiais com melhores propriedades do que os polímeros e compósitos convencionais. Dentre os novos materiais, os nanocompósitos poliméricos são de grande interesse comercial, pois podem apresentar melhor estabilidade térmica, maior resistência à chama e elevadas propriedades mecânicas, e de barreira a gases, sendo estas duas últimas com aplicabilidade direta na performance de pneus.
A partir do látex de borracha natural em combinação com nanopartículas minerais podem ser obtidos materiais por coagulação ou casting ou ainda por polimerização in situ com outros monômeros, os quais podem ser enxertados nas cadeias de poli-isopreno, conferindo novas características aos nanocompósitos formados.

Ao longo deste artigo, verificou-se que em vários estados do país são cultivados clones que apresentam maior produtividade de borracha seca e resistência ao fungo. Isto significa que pode existir também uma variabilidade regional nas propriedades da borracha. Os látices naturais podem apresentar sensível variação de composição dos microcomponentes, especialmente porque já se tem conhecimento que a composição do látex varia em função do clone, do tipo de solo, da forma de sangria. Seria sábio explorar as propriedades destas diferentes "borrachas" de forma a otimizar o desenvolvimento de novos materiais. Neste sentido a pesquisa microquímica ou microanalítica seria o caminho natural a ser seguido como rota de qualificação e quantificação destes látices. $\mathrm{Na}$ tese de doutorado de Márcia M. Rippel, ${ }^{90}$ sob orientação de Fernando Galembeck (IQ/Unicamp) foram verificados aspectos importantes de filmes e partículas de látex de clones RRIM 600 cultivados no Instituto Agronômico de Campinas. Ligações entre íons cálcio com componentes oxigenados ligados às cadeias de poli-isopreno e a presença de nanopartículas associadas ao látex, compatibilizadas por meios de componentes proteico-fosfolipídicos, são responsáveis pelas excepcionais propriedades da borracha natural.

Um outro exemplo do resultado de pesquisa acadêmica já no mercado é o Biocure ${ }^{\circledR}$ produzido pela Pele Nova Biotecnologia através da tecnologia biomembrana ${ }^{\circledR}$, patenteada em mais de 60 países. O responsável pela descoberta deste material é Joaquim Coutinho Netto, professor da USP/Ribeirão Preto. Trata-se de material ativo que induz a formação de novos vasos sanguíneos, que é a angiogênese, e de novos tecidos, chamada de neoformação, na superfície sobre a qual é aplicado. ${ }^{91}$

Por outro lado não é possível estimar no momento qual o volume de recursos anual destinado à pesquisa relacionada ao cultivo, produção, melhoramento genético, doenças e pragas, processos de extração, propriedades dos látices, tecnologias de coagulação, normatização das análises de padronização dos látices e borrachas e, também, sobre o desenvolvimento de novos materiais. Em relação a este último ponto destaca-se que o desenvolvimento de novos materiais deve ser feito focado em aplicações específicas e de importância estratégica para o país, e deve ser liderado por empresas. Por outro lado, só é possível desenvolver novos materiais conhecendo muito bem o material com o qual se trabalha, no caso os látices e borrachas naturais. Entre os tantos projetos em Hevea em andamento no Brasil, um deveria desenvolver este banco de dados.

Deve-se ainda desenvolver fontes próprias e alternativas de produção de látex natural, o que se constitui em sério investimento para a autossuficiência e desenvolvimento científico e tecnológico para o país. Infelizmente os programas nacionais atuais, especialmente o da Câmara Setorial da Cadeia Produtiva da Borracha Natural, não consideram a pesquisa e produção de outras fontes nacionais de borracha natural, como a maniçoba que não cresce nem em países da Europa e nem nos Estados Unidos.

A pesquisa no desenvolvimento de materiais de borracha natural deve receber incentivos de vulto e ser estimulada pelas agências de fomento e governo federal, da mesma forma que hoje se fomenta a pesquisa de álcool e biocombustíveis.

\section{REFERÊNCIAS}

1. van Beilen, J. B.; Poirier, Y.; Trends Biotechnol. 2007, 25, 522.

2. Greve, H-H. Em Ullmann's Encyclopedia; VCH Publishers: Deerfield Beec, 1993, vol. 23A. 
3. Cyr, D. R. Em Kirk-Othmer Encyclopedia of Chemical Technology, Wiley-Interscience: New York, 1991, vol. 20, p. 468.

4. http://www.incaper.es.gov.br/congresso_seringueira, acessada em Novembro 2007.

5. Mooibroek, H.; Cornish, K.; Appl. Microbiol. Biotechnol. 2000, 53, 355.

6. http://www.rubberstudy.com/statistics-quarstat.aspx, acessada em Janeiro 2009.

7. De Rodriguez, D. J.; Ângulo-Sanchez, J. L.; Rodriguez-Garcia, R.; $J$. Polym. Environ. 2006, 14, 37.

8. Ricardo, N. M. P. S.; Feitosa, J. P. A.; Silveira, E. R.; Neto, M. A.; Polym. Bull. 2001, 46, 107.

9. http://www.globorural.globo.com, acessada em Janeiro 2009.

10. http://www.iac.sp.gov.br/Centros/Centro_cafe/seringueira, acessada em Março 2009.

11. Devido à crise mundial no final de 2008 os preços das borrachas da Hevea caíram consideravelmente ficando abaixo dos U\$2,00 em dezembro. O preço médio antes da crise era de U\$2,40 no período de 2007 a 2008.

12. http://www.apabor.org.br, acessada em Janeiro 2009.

13. http://www.borrachanatural.agr.br, acessada em Outubro 2007.

14. http://www.yulex.com/index.html, acessada em Fevereiro 2009.

15. http://www.cpatsa.embrapa.br/catalogo/livrorg/manicobarecursosgeneticos.pdf, acessada em Março 2009.

16. http://www.faculty.ucr.edu/ legneref/botany/rubber.htm\#ceararubber, acessada em Março 2009.

17. Brydson, J. A.; Rubbery Materials and Their Compounds, Elsevier: London, 1988, cap. 4.

18. Cornish, K.; Siler, D. J.; Chemtech. 1996, 26, 38.

19. http://www.cepea.esalq.usp.br, acessada em Novembro 2007.

20. http://www.portaldoagronegocio.com.br, acessada em Março 2009.

21. http://www.apabor.org.br/sitio/artigos/index.html\#, acessada em Dezembro 2008.

22. http://www.ced.ufsc.br/emt/trabalhos/borracha/borracha/extrativismo_ arquivos/paulomorceli.pdf, acessada em Dezembro 2008.

23. http://www.apabor.org.br, acessada em Fevereiro 2009.

24. http://www.cnpdia.embrapa.br/publicacoes/download. php?file=BP08_99.pdf, acessada em Fevereiro 2009.

25. http://www.conservation.org.br, acessada em Novembro 2007.

26. http://www.cna.org.br/site/down_anexo.php?q=E22_20364jan-set-08. pdf, acessada em Março 2009.

27. http://www.omb.com.br, acessada em Março 2009.

28. http://www.cetepo.rs.senai.br, acessada em Fevereiro 2009.

29. http://www.agricultura.gov.br, acessada em Março 2009.

30. http://www.cnps.embrapa.br/cohevea/home.htm, acessada em Fevereiro 2009.

31. Mano, E. B.; Nunes, R. C. R.; Lima, L. C. O. C.; $B r N^{o} 7502614,1975$

32. Peres, A. C. C.; Nunes, R. C. R.; Visconte, L. L. Y.; Br PI 0.105.116-4, 2001.

33. Martins, A. F.; Visconte, L. L. Y.; Nunes, R. C. R.; J. Appl. Polym. Sci. 2005, 97, 2125.

34. Nunes, R. C. R.; Lopez-Gonzalez, M.; Riande, E.; J. Polym. Sci., Part B: Polym. Phys. 2005, 43, 2131.

35. Oliveira, F. A.; Alves, N.; Giacometti, J. A.; Constantino, C. J. L.; Mattoso, L. H. C.; Man, A. M. O. A.; Job, A. E.; J. Applied Polym. Sci. 2007, 106, 1001.

36. Rippel, M. M.; Valadares, L. F.; Murakami, M. M.; Galembeck, F.; $B r$ PI 0.301.193-3, 2003.

37. Schumacher, H. C.; Rippel, M. M.; Galembeck, F.; Br PI No 0.706.080, 2007.

38. Bragança, F. C.; Murakami, M. M.; Galembeck, F.; Br Protocolo $N^{o}$ 018.070.016.455, 2007

39. Jacob, M.; Varughese, K. T.; Thomas, S.; J. Mater. Sci. 2006, 41 , 5538.
40. Angellier, H.; Molina-Boisseau, S.; Dufresne, A.; Macromolecules 2005, 38, 9161.

41. Labet, M.; Thielemans, W.; Dufresne, A.; Biomacromolecules 2007, 8, 2916.

42. Viguie, J.; Molina-Boisseau, S.; Dufresne, A.; Macromol. Biosci. 2007, $7,1206$.

43. Latif, F.; Aziz, M.; Katun, N.; Ali, A. M.; Yahya, M. Z.; J. Power Sources 2006, 159, 1401.

44. Fakhru'l-Razi, A.; Atieh, M. A.; Girun, N.; Chuah, T. G.; El-Sadig. M.; Biak, D. R. A.; Compos. Struct. 2006, 75, 496.

45. Kueseng, K.; Jacob, K. I.; Eur. Polym. J. 2006, 42, 220.

46. Cho, B. H.; Hwang, I. R.; Lee, Y. S.; Jeong, J. M.; Son, K. J.; Nah, C.; J. Nanosci. Nanotechnol. 2008, 8, 5516.

47. Sui, G.; Zhong, W. H.; Yang, X. P.; Yu, Y. H.; Zhao, S. H.; Polym. Adv. Technol. 2008, 19, 1543

48. Sato, Y.; Hasegawa, K.; Nodasaka, Y.; Motomiya, K., Namura, M.; Ito, N.; Jeyadevan, B.; Tohji, K.; Carbon 2008, 46, 1509.

49. Bragança, F. D.; Valadares, L. F.; Leite, C. A. D.; Galembeck, F.; Chem. Mater. 2007, 19, 3334.

50. Valadares, L. F.; Linares, E. M.; Bragança, F. C.; Galembeck, F.; J. Phys. Chem. C 2008, 112, 8534.

51. Fornes, T. D.; Yoon, P. J.; Keskkula, H.; Paul, D. R.; Polymer 2001, 42 , 9929.

52. Xu, Y. J.; Brittain, W. J.; Vaia, R. A.; Price, G.; Polymer 2006, 47, 4564.

53. Chou, C-J.; Garcia-Meitin, E. I.; Schilhab, L.; US pat. 7,084,199 2006.

54. Sheng, N.; Boyce, M. C.; Parks, D. M.; Rutledge, G. C.; Abes, J. I.; Cohen, R. E.; Polymer 2004, 45, 487.

55. Huang, J-C.; Zhu, Z-K.; Yin, J.; Qian, X. F.; Sun, Y. Y.; Polymer 2001, 42,873 .

56. Lan, T.; Westphal, E. K.; Psihogios, V.; US pat. 6,399,690 2000.

57. Huskic, M.; Zigon, M.; Eur. Polym. J. 2007, 43, 4891.

58. Takekoshi, T.; Bahr, S. R.; US pat. 2,006,205,916 2006.

59. Bhole, Y. S.; Wanjale, S. D.; Kharul, U. K.; Jog, J. P.; J. Membr. Sci. 2007, 306, 277.

60. Brody, A. L.; Food Technol. 2007, 61, 80.

61. Xu, B.; Zheng, Q.; Song, Y. H.; Shangguan, Y.; Polymer 2006, 47, 2904.

62. Kint, D. P. R.; Seeley, G.; Gio-Batta, M.; Burgess, A. N.; J. Macromol. Sci., Part B: Phys. 2005, B44, 1021.

63. Ding, Y. Y.; Gui, Z.; Zhu, E.; Wang, Z. Z.; Hu, Y.; Song, L.; J. Mater. Res. 2007, 22, 3316.

64. Maruo, K.; Kanda, T.; Mitadera, J.; Liang, Y.; Lan, T.; US pat. 2,007,049,680 2007.

65. Morgan, A. B.; Chu, L. L.; Harris, J. D.; Fire Mater. 2005, 29, 213.

66. Majumdar, D.; Dontula, N.; Blanton, T. N.; Freedman, G. S.; EP pat. 1,312,582 2003.

67. Hackman, I.; Hollaway, L.; Composites Part A 2006, 37, 1161.

68. Goettler, L. A.; Lee, K. Y.; Thakkar, H.; Polym. Rev. 2007, 47, 291.

69. Gong; C.; Neagu, C.; Poole, B. J.; Dias, A. J.; Karp, K. R.; Johnston, M. W.; US pat. 2,008,009,579 2008.

70. Mizuno, Y.; Kondo, T.; WO Pat. 2,008,149,585 2008

71. Yang, X.; Cohen, M. P.; Senyek, M. L.; Parker, D. K.; Cronin, S. W.; Lurich, L. T.; Francik, P.; Gurec, C.; US pat. 2,005,065,266 2005.

72. O'leary, R.; Korwin-Edson, M. L.; WO pat. 2,008,082,618 2008.

73. Magaraphan, R.; Thaijaroen, W.; Lim-Ochakun, R.; Rubber Chem. Technol. 2003, 76, 406.

74. Varguhese, S.; Karger-Kocsis, J.; Polymer 2003, 44, 4921.

75. Wang, Y. Q.; Zhang, H. F.; Wu, Y. P.; Yang, J.; Zhang, L. Q.; J. Appl. Polym. Sci. 2005, 96, 318.

76. Zhang, L.; Wang, Y.; Yu, D.; CN pat. 1,238,353 1998.

77. Wu,Y. P.; Jia, Q. X.; Yu, D. S.; Zhang, L.Q.; J. Appl. Polym. Sci. 2003, 89,3855 
78. Liang, Y. R.; Wang, Y. Q.; Wu, Y. P.; Lu, Y. L.; Zhang, H. F.; Zhang, L. Q.; Polym. Test. 2005, 24, 12.

79. Zhang, H. F.; Wang, Y. Q.; Wu, Y. P.; Zhang, L. Q.; Yang, J.; J. Appl. Polym. Sci. 2005, 97, 844.

80. Wang, Y. Q.; Zhang, H. F.; Wu, Y. P.; Yang, J.; Zhang, L. Q.; Eur. Polym. J. 2005, 41, 2776.

81. Ma, Y.; Wu, Y. P.; Wang, Y. Q.; Zhang, L. Q.; J. Appl. Polym. Sci. 2006, 99, 914.

82. Clarey, M.; Tsipursky, S. J.; Beall, G. W.; Eisenhour, D. D.; Edwards, J.; US pat. 6,050,509 2000.

83. Lopez-Machado, M. A.; Arroyo, M.; Herrero, B.; Biagiotti J.; J. Appl. Polym. Sci. 2003, 89, 1.
84. Teh, P. L.; Mohd Isak, Z. A.; Hashim, A. S.; Karger-Kocsis, J.; Ishiaku, U. S.; J. Appl. Polym. Sci. 2004, 94, 2438.

85. Zhao, J.; Crawford, M. J.; Puhala, A. S.; Cohen, M. P.; US pat. 7,473,728 2009 .

86. Tsunoda, K.; Mashita, S.; Takano, N.; JP pat. 2,003,292,678 2003.

87. http://www.inmat.com/, acessada em Fevereiro 2009.

88. http://www.orbys.com.br/, acessada em Fevereiro 2009

89. Bragança, F. C.; Tese de Doutorado, Universidade Estadual de Campinas, Brasil, 2008.

90. Rippel, M. M.; Tese de Doutorado, Universidade Estadual de Campinas, Brasil, 2005.

91. http://www.pelenova.com.br, acessada em Fevereiro 2009. 